The chemical, physical, immunological and toxic properties of the substance obtained from the culture medium in which $E$. coli $K 235$ is grown indicate that the material having colicine $K$ activity is the somatic or $O$ antigen of the bacillus. The fact that this complex has potent antibiotic properties seems at first sight extraordinary. Yet it should not be forgotten that $O$ antigens of Gram-negative bacill exert potent toxic effects upon certain mammalian species. It is not inconceivable, therefore, that they might exert a similar effect upon an occasional bacterial species.

It cannot yet be said with complete certainty, however, that colicine activity is an inherent property of the $O$ antigen of $E$. coli $K 235$. It is possible that colicine $K$ is in reality a distinct molecular species bound to the lipocarbohydrate protein complex. If this is the case, the union is firm, and has until now defied attempts at dissociation. From the evidence at hand, however, we are at the moment inclined to favour the first point of view.

Walther F. Goebel

GuY T. Barry

MARgFris A. JeSAitis

Eltzabeth M. MTLLER

Rockefeller Institute for Medical Research, New York.

May 23.

${ }^{1}$ Gratia, A., C.R. Soc. Biol., 93, 138 (1925).

${ }^{2}$ Fredericq, P., Rev. Belge Pathol. Méd. Exp., 19, Supp. iv (1948).

${ }^{3}$ Fredericq, P., C.R. Soc. Biol., 142, 543 (1948).

${ }^{4} \mathrm{Jacob}, \mathrm{F}$., Lwoff, A., Siminovitch, L., and Wollman, E., Ann. Inst. Past., 84, 222 (1953).

${ }^{6}$ Fredericq, P., and Gratia, A., C.R. Soc. Biol., 143, 560 (1949). Fredericq, P., ibid., 148, 1001, 1014 (1949).

- Jacob, F., Siminovitch, L., and Wollman, E., Ann. Inst. Past., 83,295 (1952).

'Fredericq, P., Ann. Inst. Past., 84, 294 (1953).

${ }^{8}$ Fredericq, P., and Gratia, A., Ant. van Leewwenhoek, 16, 119 (1950). Fredericq, P., C.R. Soc. Biol., 146, 1624 (1952).

- Fredericg, P., C.R. Soc. Biol., 142, 403 (1948). Jacob, F., "Les Bactéries Lysogènes et la Notion de Provirus", Monographies de l'Inst. Past. (Masson et Cie, Paris, 1954).

${ }^{10}$ Longsworth, L. G., and MacInnes, D. A., J. Bact., 29, 595 (1935).

\section{Anti-acetylcholine and Anti-histamine Actions of the Total Alkaloids of Rauwolfia serpentina Benth}

Dasgupta, Ray, Roy and Werner ${ }^{1}$, Mukherjee and the present authors ${ }^{z}$ have made certain observations on the anti-adrenaline effect of extracts of Rauwolfia serpentina, but their effects on the action of acetylcholine or of histamine have not yet been reported. Experiments have been carried out on isolated strips of guinea pig ileum in Dale's bath, containing oxygenated Ringer-Locke's solution at $35^{\circ} \mathrm{C}$., and the modifications caused by varying concentrations $\left(10^{-6}\right.$ to $10^{-4} \mathrm{gm} . / \mathrm{ml}$.) of extracts of Rauwolfia serpentina (total alkaloids extracted in 2 per cent hydrochloric acid) on the action of acetylcholine $\left(10^{-8} \mathrm{gm} . / \mathrm{ml}\right.$.) or of histamine $\left(10^{-8}\right.$ to $10^{-7} \mathrm{gm} . / \mathrm{ml}$.) were studied. The extracts produced, by themselves, a definite but slight and transient contraction of the intestine. Dasgupta et al. ${ }^{1}$ did not, however, find any stimulating effect on intestine in situ, whereas Chopra, Gupta and Mukherjee ${ }^{4}$ mention a stimulating property of the extract on such a preparation. (Dr. R. P. Banerjee, of the Indian Council for Medical Research, prepared extracts of Rauwolfia serpentina in three different concentrations of hydrochloric acid (namely, 2, 5 and 10 per cent) with the view of fractionating the different active principles. The results obtained with an extract in 2 per cent hydrochloric acid are described here; those with 5 and 10 per cent acid extracts are under investigation.)

Anti-acetylcholine action. In all of the twelve experiments carried out, there was a greater degree of inhibition of the action of acetylcholine in the presence of the higher concentration of the extract of Rauwolfia in the bath, when the former was applied $30-50 \mathrm{sec}$. after the administration of the extract to the bath fluid. A concentration of the extract of $5 \times 10^{-5} \mathrm{gm}$. $/ \mathrm{ml}$. and stronger completely annulled the effect of $10^{-8} \mathrm{gm} . / \mathrm{ml}$. acetylcholine.

Anti-histaminic action. The results with histamine applied 30-50 sec. after Rauwolfia extract were similar to those with acetylcholine mentioned above. The extract of Rauwolfia in concentrations of $5 \times 10^{-5} \mathrm{gm} . / \mathrm{ml}$. and stronger inhibited the action of histamine $\left(10^{-8}\right.$ or $5 \times 10^{-8} \mathrm{gm} . / \mathrm{ml}$.). A stage of slight potentiation of the action of both acetylcholine and histamine was noted in a few cases during the phase of recovery of the action of acetylcholine and histamine on repeated changing of the bath fluid, after an earlier observation of the action in the presence of Rauwolfia extract.

\section{L. Chatterjee \\ H. F. HÄUSLER}

Department of Pharmacology,

School of Tropical Medicine, Calcutta.

1 Dasgupta, S. R., Ray, G. K., Roy, P. K., and Werner, G., Ind. $J$ Med. Res., 7,229 (1953).

- Mukherjee, J. N., Nature, 172, 867 (1953).

${ }^{3}$ Chatterjee, M. L., and Häusler, H. F., Bull. Calcutta School Trop. Med., 3, 70 (1955).

- Chopra, R. N., Gupta, J. C., and Mukherjee, B., Ind. J. Med. Res. 21, 261 (1933)

\section{'Kernechtrot' or Nuclear Fast Red in the Histochemical Detection of Calcareous Corpuscles in Taenia saginata}

Taenia saginata, like many other cestodes ${ }^{1}$, is known to contain numerous calcareous corpuscles or calcium balls distributed throughout the parenchyma. These corpuscles, in addition to their calcium content, consist of an organic base, containing ${ }^{2}$ deoxyribo- and ribo-nucleic acids, simple proteins, glycogen and a hyaluronic acid-type of polysaccharide. With Gomori's modified technique these corpuscles also gave a positive reaction for alkaline phosphatase. The presence of calcium in these balls was indicated by von Kossa's silver test for calcium ${ }^{3}$.

McGee-Russell ${ }^{4}$ has recently reported the selective affinity of 'Kernechtrot' or nuclear fast red (batch 3569 ) for soluble inorganic calcium salts and its use in the histochemical detection of calcium.

We have tried to confirm the specificity of this dye by using the proglottids of $T$. saginata with their calcium-containing corpuscles as test material. It has been observed that the dye stains these corpuscles, and in some cases their immediate neighbourhood, brilliant red. (see Fig. 1). As an experimental control we have stained in a similar manner identical sections of the same tissues after previous treatment with citrate buffer $(p H 4 \cdot 5-5)$ to remove calcium. The corpuscles failed to take up the dye in this case. This observation therefore confirms the conclusion regard. ing specificity of the dye for detecting calcium in the tissues. A detailed account of this work will be published elsewhere. 